\title{
Correction to: Duality for quasiconvex minimization over closed convex cones
}

\author{
Juan Enrique Martínez-Legaz ${ }^{1,2}$ • Wilfredo Sosa ${ }^{3}$
}

Published online: 16 July 2021

๑) Springer-Verlag GmbH Germany, part of Springer Nature 2021

\section{Correction to: Optim Lett}

\section{https://doi.org/10.1007/s11590-021-01766-5}

The original publication contains several inaccuracies and minor but important mistakes, which are worth correcting:

- On the last line of the statements of Theorems 8 and 9, the text " $\left\langle x_{0}, x^{*}\right\rangle \geq 0$ and" should be deleted, as the condition $\left\langle x_{0}, x^{*}\right\rangle \geq 0$ is redundant, since, in both statements, one has $x_{0} \in K$ and $x^{*} \in K^{+}$. Therefore, those last lines should simply read

$$
f\left(x_{0}\right)=\min _{\left\langle x, x^{*}\right\rangle \geq 0} f(x) .
$$

- On the 4 th line of the 13 th page, one has to replace " $c\left(x,\left(x^{*}, \alpha\right)\right)$ " with "c $c\left(u,\left(x^{*}, \alpha\right)\right)$."

- On the 13th page, one has to delete the 7 th line before Theorem 13, which reads

"We will denote this particular instance of $D(f, K)$ by $D_{0}(f, K)$."

The actual problem $D_{0}$ is introduced later, after Theorem 14 .

- In the equivalence stated in Theorem 13 , one has to replace " $D_{0}$ " with " $D$."

The original article can be found online at https://doi.org/10.1007/s11590-021-01766-5.

$凶 \quad$ Juan Enrique Martínez-Legaz

juanenrique.martinez.legaz@uab.cat

Wilfredo Sosa

sosa@p.ucb.br; sosa@imca.edu.pe

1 Departament d'Economia i d'Història Econòmica, Universitat Autònoma de Barcelona, Bellaterra, Spain

2 Barcelona Graduate School of Mathematics (BGSMath), Barcelona, Spain

3 Graduate School in Economics, Catholic University of Brasilia, SGAN 916 - Modulo B, 70790-000 Brasilia, DF, Brazil 
- On the last lines of the statements of Theorems 13 and 14, one has to add "and $\min \left\{\left\langle x, x^{*}\right\rangle, \alpha\right\}=\min \{0, \alpha\}$;" thus, they should read

$$
\left(x^{*}, \alpha\right) \in \partial_{c} f(x) \text { and } \min \left\{\left\langle x, x^{*}\right\rangle, \alpha\right\}=\min \{0, \alpha\} .
$$

- In Theorem 17, one has to replace " $D(f, K)$ " with " $D_{0}(f, K)$ " twice.

Publisher's Note Springer Nature remains neutral with regard to jurisdictional claims in published maps and institutional affiliations. 